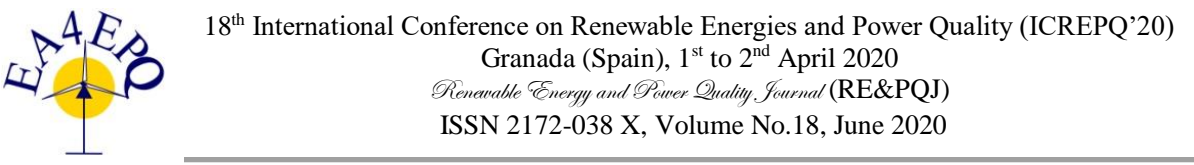

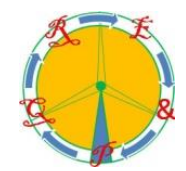

\title{
Vibration and freeze - thaw cycling tests to characterize PEM fuel cells stacks to use in vehicles
}

J.M. Olavarrieta ${ }^{1}$, G. Rodado ${ }^{1}$

${ }^{1}$ Applied Engineering Unit

The National Hydrogen Center (CNH2)

Prolongacion Fernando el Santo s/n, 13500 Puertollano (Spain)

Phone number: +0034926 420682, e-mail: Josemaria.olavarrieta@cnh2.es, Gema.rodado@cnh2.es

\begin{abstract}
The main objective of this work is to test and characterize a $5 \mathrm{kWe}$ PEM fuel cell stack before and after being subjected to vibrations and freeze-thaw cycles in order to determinate their performance, safety and durability.

To carry out these activities, different test procedures were developed and validated in $\mathrm{CNH} 2$ facilities by following several international works, projects and normative. They were used and applied in the following equipment: 1) Vibration platform (shaker) for vibration test analysis on fuel cells in three axes directions with different vibration profiles; 2) Walk-in climatic chamber to test the starting, operating and stopping behaviour of fuel cells under defined extreme conditions. 3) Test station designed and developed by the $\mathrm{CNH} 2$ to test and characterize PEM fuel cell stacks up to $10 \mathrm{kWe}$.
\end{abstract}

After conducting the tests, the results indicated that the severe variations of temperature as well as the applied vibrations on the stack did not affect its performance and external integrity, so the stack could be installed into an automotive application with the security that it will response as expected.

Keywords. Climatic chamber, PEM fuel cell, shaker, vibration, freeze-thaw tests.

\section{Introduction}

Hydrogen fuel cell technologies have experienced a great boost for last decades, significantly increasing the production of these devices for both stationary and transport applications, influenced by two main reasons: environmental pollution and energy shortage.

A fuel cell is an electrochemical device that converts chemical energy directly into electricity by using hydrogen and oxygen gases as reactive components and obtaining water and heat as by-products of the chemical reaction. Fuel cells, specifically those of Proton Exchange Membrane (PEM) technology, are considered an alternative to internal combustion engines, mainly because of the low emissions they produce (almost zero), high efficiency and low operating temperatures $\left(<100{ }^{\circ} \mathrm{C}\right)$.

However, the introduction and use of fuel cells in the automotive market require the development of standardized and validated procedures which must be applied to test and evaluate the fuel cell performance, safety and durability in different environmental conditions including vibrations and freeze - thaw cycles.

In this work the $\mathrm{CNH} 2$ researches evaluated the behaviour and performance of a $5 \mathrm{kWe}$ PEM fuel cell stack as initial testing sample and scale-up the electric power of the fuel cell to be placed in vehicles.

\section{Experimental installation}

The activities involved and described in this document were carry out by using the following equipment:

\section{A. Test station for $1-10 \mathrm{kWe}$ PEM fuel cell stacks}

The facility shown in fig.1, whose main technical specifications are listed at table $I$, is a test bench designed, developed and builtup at the $\mathrm{CNH} 2$ in order to test PEMFC stacks by following different procedures, including those contained in [1],

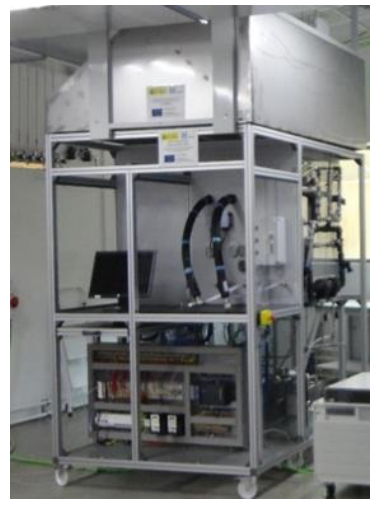

Fig. 1. Test station for $1-10 \mathrm{~kW}$ PEMFC stacks

Table I. - Technical specifications of $1-10 \mathrm{~kW}$ PEM fuel cell stack test station

\begin{tabular}{|l|c|c|}
\hline Characteristic & Value & Unit \\
\hline Electric power range & $1-10$ & $\mathrm{~kW}$ \\
\hline Electric current range & $0-300$ & $\mathrm{~A}$ \\
\hline Electric voltage range & $0-160$ & $\mathrm{~V}$ \\
\hline Number of cells & $\leq 130$ & --- \\
\hline Working temperature range & $\leq 70$ & ${ }^{\circ} \mathrm{C}$ \\
\hline Working pressure range & $0-2$ & bar $_{\mathrm{g}}$ \\
\hline Working HR range & $0-100$ & $\%$ \\
\hline Cooling system & \multicolumn{2}{|c|}{ Water / air } \\
\hline
\end{tabular}




\section{B. Vibration platform (shaker)}

This vibration platform shown in fig. 2 generates movement on vertical, longitudinal and lateral axes (by using a sliding table) to study the response of a fuel cell stack (non-operating mode) under simulated vibration profiles, identifying resonance frequencies to check and optimize the structural integrity of the sample. The main technical specifications of the shaker are shown in Table II.

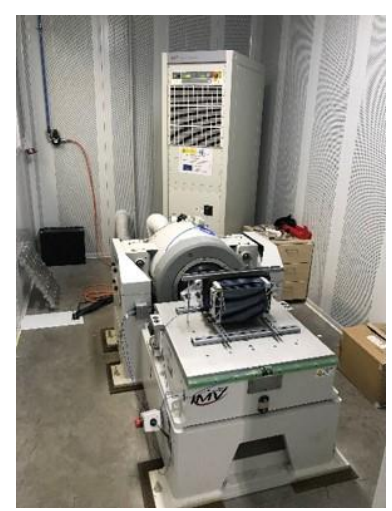

Fig. 2. Vibration platform (shaker)

Table II. - Technical specifications of the shaker

\begin{tabular}{|l|c|c|}
\hline Characteristic & Value & Unit \\
\hline Frequency range & $0-2200$ & $\mathrm{~Hz}$ \\
\hline Max. force rating & 8 & $\mathrm{kN}$ \\
\hline Max. displacement & 60 & $\mathrm{~mm}$ \\
\hline Max. velocity (sine / shock) & $2,2 / 3,5$ & $\mathrm{~m} / \mathrm{s}$ \\
\hline Max. load support & 200 & $\mathrm{~kg}$ \\
\hline Sliding table dimensions & $630 \times 630 \times 30$ & $\mathrm{~mm}$ \\
\hline Vertical table diameter & 190 & $\mathrm{~mm}$ \\
\hline
\end{tabular}

\section{Walk-in climate chamber}

The walk-in climate chamber shown in fig.3, whose technical characteristics are listed on table III, allows to test fuel cell devices by fixing specific environmental conditions, studying the start-up and the operation stages of fuel cells and auxiliary components, long-term and accelerated aging testing through temperature

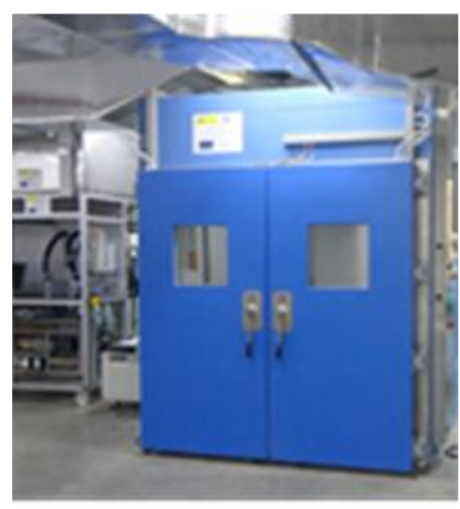
humidity cycling.

Fig. 3. Walk in climate chamber

Table III. - Technical specifications of the climate chamber

\begin{tabular}{|l|c|c|}
\hline Characteristic & Value & Unit \\
\hline Temperature test range & $-40-80$ & ${ }^{\circ} \mathrm{C}$ \\
\hline $\begin{array}{l}\text { Humidity test range from } \\
10^{\circ} \mathrm{C}\end{array}$ & $10-95$ & $\%$ \\
\hline $\begin{array}{l}\text { Programable temperature } \\
\text { ramps up and down rate }\end{array}$ & $3,8 / 1,4$ & ${ }^{\circ} \mathrm{C} / \mathrm{min}$ \\
\hline Working dimensions & $2360 \times 3240 \times 2800$ & $\mathrm{~mm}$ \\
\hline Useful volume & 16 & $\mathrm{~m}^{3}$ \\
\hline
\end{tabular}

\section{Results}

The resonance frequency search test conducted in the range $7-200 \mathrm{~Hz}$ and acceleration of $1 \mathrm{~g}$ detected different resonance peaks in the three axes direction as shown in fig.4. This indicates that the mechanical properties of the fuel cell stack could be damaged if exposed for long periods of time to the detected resonance frequencies, mainly at the values of 65,50 and $99 \mathrm{~Hz}$ where the stack experienced the highest peaks.

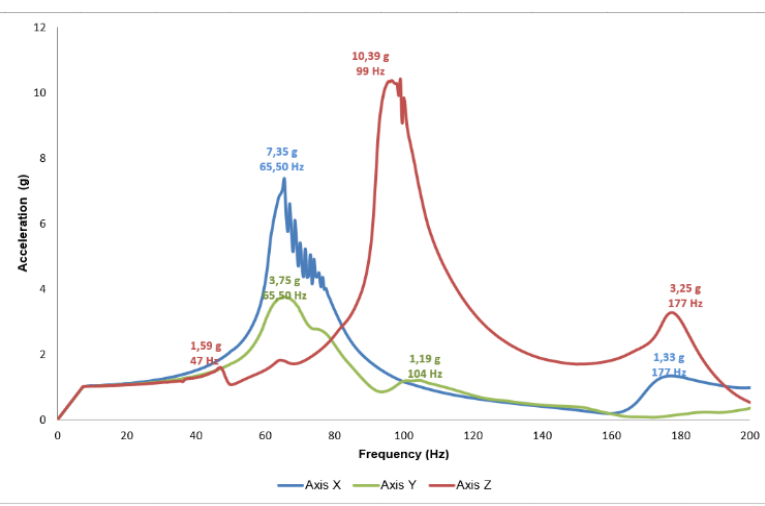

Fig. 4. Resonance sweep test in the three axes

After being found the resonance frequencies, vibration tests in sine mode were carried out by following the profile shown in fig. 5 .

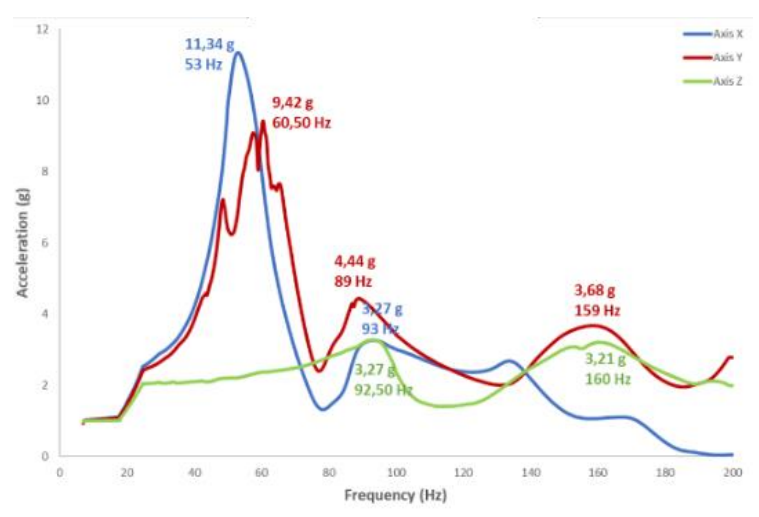

Fig. 5. Resonance profile for vibration test in sine mode

Internal gas leakage test was conducted before and after the vibration test at the anode compartment by using helium gas in the test station described in experimental installation part. To carry out the test in the anode compartment, the outlet of the anode compartment was closed and pressurised up to 0,4 bar $_{\mathrm{g}}$ pressure.

The cathode and cooling compartments outlets were left open to ambient and the pressure was held constant. After 5 minutes, the value of the measured leakage rate stayed constant and was recorded. The average gas leakage rates obtained were: $8,59 \mathrm{Nml} / \mathrm{min}$ and 7,47 Nml/min before and after the vibration test. 


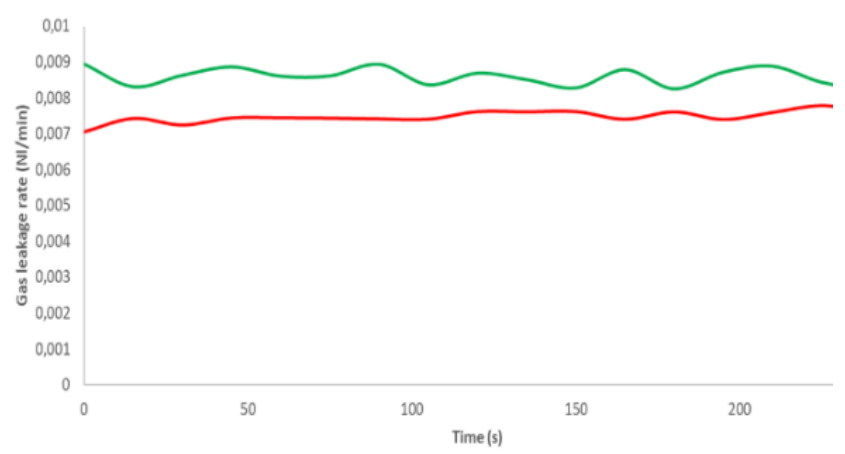

—Leakage rate after vibration tests —Leakage rate before vibration tests

Fig. 6. Results of leakage test before and after vibration test

After these vibration test and leakage test (in that order for safety reasons), performance test was developed in order to discover if the vibrations affected the functioning of the fuel cell stack, obtaining the results shown in fig.7, where it can be observed that the results obtained are very similar.

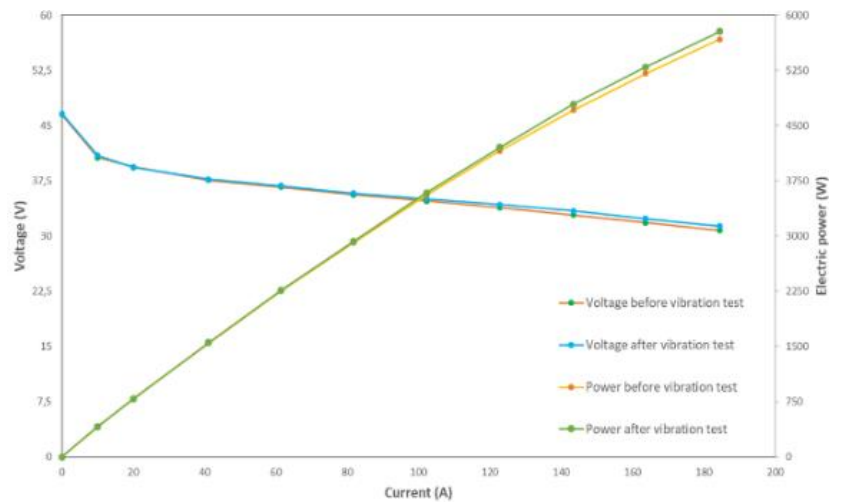

Fig. 7. Results of performance test before and after vibration test

As part of this work, freeze - thaw cycling test was conducted in order to discover if severe changes of temperature affected both the mechanical integrity and the performance of the fuel cell stack. Firstly, the stack was subjected to the freeze - thaw cycle profile shown in fig. 8 .

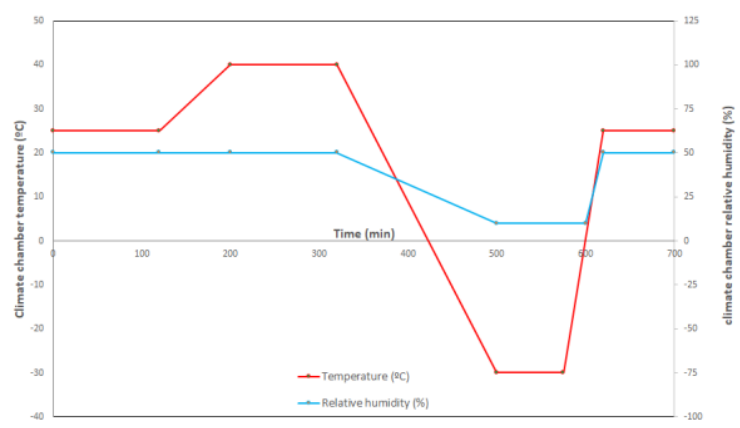

Fig. 8. Freeze - thaw cycle profile

Later, gas leakage and polarization and power curves were determined (in that order) before and after each test, obtaining almost the same leak values and the performance variation shown in fig.9 and fig. 10.
It was considered that, the initial points for the leakage and performance tests in this part; are the same values than the results obtained in the vibration test part.

In addition to this, the test conditions for both leakage test and performance test were the same conditions than the ones set for vibration test.

Take this into account, the results obtained for this freeze - thaw test part are shown in fig.9 and fig. 10.

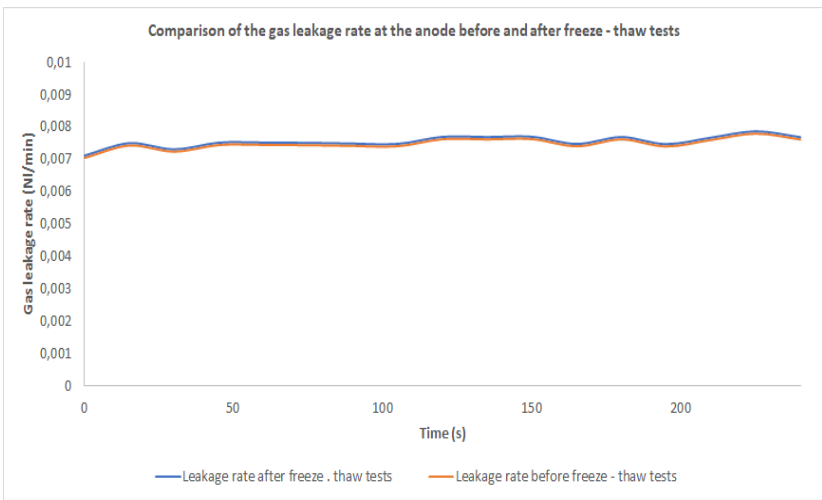

Fig. 9. Results of leakage test before and after freeze - thaw test

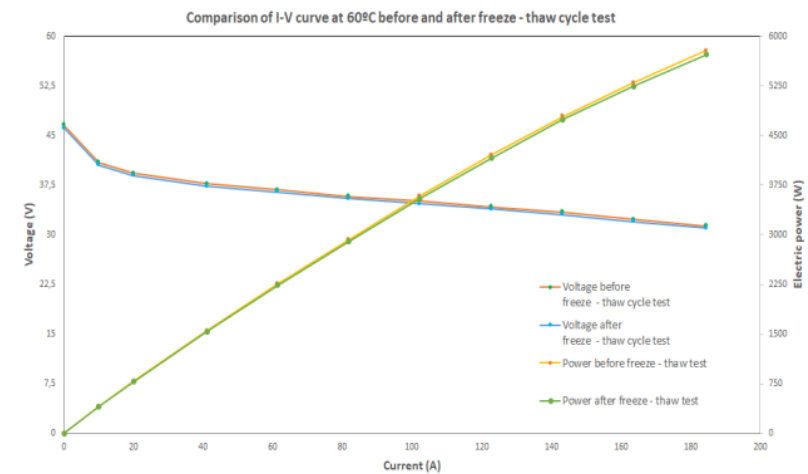

Fig. 10. Results of performance test before and after freeze thaw test

Regarding the fig. 9 the average leakage rate obtained were $7,47 \mathrm{Nml} / \mathrm{min}$ and $7,54 \mathrm{Nml} / \mathrm{min}$ before and after the test.

Regarding the fig. 10 where it is shown the performance test results, it can be said that the functioning was almost the same. Very similar results were obtained with just around $1 \%$ difference between the $\mathrm{I}-\mathrm{V}$ curves before and after tests. This can be attributed to some reasons such as the usual degradation of the stack, difference due to average of measure devices, very low difference of temperature, relative humidity, etc. what conduct to this very low difference but, in conclusion, any difference to be considered.

\section{Conclusions}

As shown in pictures from part 3, the most important conclusions could be summarized by affirming that the stack did not suffer any external or internal damage, not 
only for finding no external deformation, fracture, etc. but internal damage or several degradations more than expected, that could produce leaks with the consequent risk for the user and the system. The more significant indicator is the not finding or obtaining very high level of leakage in the channels where the gases go through.

In addition to this, the I-V and I-P curves results showed that the vibrations and freeze - thaw cycles did not affect the stack performance, which means the equipment could work in extreme conditions in a proper manner. In this context the difference of performance from the initial point of vibration test to the end of freeze - thaw test was less than $1,5 \%$ at the same conditions of functioning, something that may be due to the accuracy of the measure devices, very light differences of working conditions, expected and usual degradation of the fuel cell components or, more probably, a set of all of them.

Finally, it could be said that, if the fuel cell is placed in an automotive vehicle to be run in severe conditions, not only regarding the road but the ambient conditions, the fuel cell should work perfectly within than expected without problems.

\section{Acknowledgement}

The test ring, the shaker and the walk-in climate chamber included within PEM testing laboratory, is financed jointly with the Spanish Ministry of Economy and Competitiveness (MINECO), Castilla-La Mancha Government (JCCM) and the European Regional Development Fund (ERDF) 2007-2013 included in the "Programa Operativo de I+D+I por y para el beneficio de las empresas - Fondo Tecnológico".

\section{References}

[1] UNE - EN IEC 62282-2. Fuel Cell Technologies - Part 2: Fuel cell modules. December 2012.

[2] J. Hunger, T. Jungmann, STACK-TEST Project no 303445. Test module S-02: Vibration test. August 2015.

[3] J. Hunger, T. Jungmann, STACK-TEST Project $n^{\circ} 303445$.

Test module S-04: Freeze - thaw cycling test. August 2015. 